\title{
Dynamic Optimal Production Strategies Based on the Inventory-Dependent Demand under the Cap-and-Trade Mechanism
}

\author{
Qiuzhuo Ma, Haiqing Song, and Gongyu Chen \\ Department of Logistics Engineering and Management, Lingnan College, Sun Yat-sen University, Guangzhou 510275, China \\ Correspondence should be addressed to Qiuzhuo Ma; maqzh@mail2.sysu.edu.cn
}

Received 31 December 2013; Accepted 16 February 2014; Published 7 May 2014

Academic Editor: Piermarco Cannarsa

Copyright (C) 2014 Qiuzhuo Ma et al. This is an open access article distributed under the Creative Commons Attribution License, which permits unrestricted use, distribution, and reproduction in any medium, provided the original work is properly cited.

Cap-and-trade system is the most popularly applied mechanism that is currently recognized to be effective in stimulating the enterprises to environmentally friendly operate through emission reduction. In this paper, we consider a single company whose carbon emission is generated from not only its production process but also its inventory management activity. A continuous optimal control model is used to find the optimal dynamic production policy on the objective of profit maximization with respect to the cap-and-trade mechanism. Some properties of the strategies are derived concerning the timing of production rate adjustment and the length of the decision duration period. The capacitated strategy is also discussed, in which different combinations of different decision intervals of different production rates are explicitly explored. The impact of various factors on the length of these intervals is qualitatively described. Through the sensitivity analysis, we further discuss the impact of product prices on the positions of the switch time points between the decision intervals. Company's performance including profit and emission is numerically compared in the situation of joining or not joining the cap-and-trade system.

\section{Introduction}

Recently, affected by the increasing emphasis on the issues of climate change, governments have been working on the efficient balance between environment quality and economic development. The European Union (EU), since the implementation of the greenhouse gas emissions trading scheme (namely, the EU ETS) in January 1, 2005, has treated the carbon emission as a commodity circulating in EU market through adopting the cap-and-trade system. This system was originally used as an economic incentive to encourage the injurisdiction enterprises to take measures of emission reduction. According to Field's perspective [1], to governments, emission trading is one of the combined environmental mechanisms. In such a mechanism, enterprises with better performance in terms of carbon emission have the right to locally or internationally sell their emission credits to the international market, whereas the poor performer may need to purchase the difference between its emission and the cap. Much of the current research focuses on firm's production and inventory strategies under low-carbon policies but only individually considers the operational impact from each side.

In this paper, we are motivated to synthetically consider the impacts of inventory management activities and production process on the carbon emission and further the optimal dynamic production strategies.

The rest of this paper is organized as follows: in Section 2, we provide a review on the related literatures; the problem is described in Section 3 with some key assumptions; in Section 4, we construct an optimal control model to explore the dynamic optimal production and inventory management strategy; in Section 5, a numerical analysis is presented and we conclude the whole paper while making a summary on the limitations in Section 6.

\section{Literature Review}

There are a number of studies dedicated to the decisionmaking issues under the framework of dynamic control. Recent studies include Sana's [2-4], in which the author 
built an EOQ model over a finite time horizon within a dynamic control system. The demand in the paper was assumed to be uniformly distributed and set to depend on the price over the replenishment period. Differently, Sana [2-5] assumed that the demand is display space as well as sellingprice dependent within an EOQ system where the tradeoffs between inventory costs, purchasing costs, the cost of sales staff efforts, and selling price were considered. Bukhari and EI-Gohary [6] constructed an optimal control model of production-maintenance system with deteriorating products for exploring the optimal production and maintenance strategies within the schedule. Shoude [7] extended EI-Gohary's framework to a more general fashion in which the emission tax and pollution R\&D investment are considered as decision variables. Early similar studies can be traced to Laffont and Tirole [8] in which the authors highlighted the impact of the existing and imminent carbon trading market on enterprise's strategies of pollution abatement and production. The results state that the current emission trading market is able to enhance the firm's emission-reduction efforts but the imminent completion mechanism will, if known by the company, weaken its enthusiasm of the pollution-abatement investment. For this issue, the authors, from the perspective of mechanism design, provided us with some measures and recommendations on how to simultaneously analyze the universality of these proposals. These papers essentially focus on the impact of external and internal emission reduction activities on firm's performances. Caetano et al. [9] presented a study of the resource management on emission reduction by constructing an optimal control model. Although the paper discussed the dynamic relation between $\mathrm{CO}_{2}$ emission and the reforestation investment and clean technology development, it involves less production and operation. Compared with the above literatures, we do not either directly use the EOQ framework or take any emission policies as the decision variables, but we contribute more on the study that concerns the balance between the environmental and commercial performances. Besides, according to many of the existing literatures, this paper should be a forerunner in synthetically modeling the relationship between emission, inventory, and production among the researches of utilizing a continuous optimal control on low-carbon issues. Moreover, we in this paper zoom in on some specific operation activities. The analysis and result are expected to be more constructive in conducting company's production and inventory management. Similar works include Dobos's [10], in which the author took use of a concave production cost function in developing the firm's optimal production strategy under the policies of carbon tax and emission standard. The study made a comparison between the optimal solutions derived from both the original and modified versions from Arrow-Karlin's research [11]. Dobos [12-14] addressed a similar extension on the classical A-K model by transforming the cost term into a convex form. In these studies, the generation of carbon emission is separately considered with production, which ignores the relationship between emission and inventory processing. However, in practice among the companies such as Hyundai Motors Corporate, a carbon footprint over the whole supply chain of motor manufacturing has to be considered. Namely, the emission performance through the production process of the mobile components needs to be measured and monitored [15]. In our model, the influences of production and inventory processing on emission are synthetically simulated. Namely, we abstracted the carbon footprint over a manufacturing supply chain into two connected major operation activities, that is, production and inventory processing. In fact, we find in the previous studies that while the modeling process does reach the enterprise side, the interest on the impact of the government policies on the firm's strategies is mainly discussed. According to Gray and Shadbegian [16], pollution control and productive investment should be integrated although the former will sometimes "crowd out" the latter on the empirical study. Chen and Monahan [17] analyzed the shortcomings of emission standard policy claiming that people are paying too much attention to the validity of the policies compared to the reduction marginal cost. For the other one, even though we can control the emission by the end of the planning horizon, other kinds of pollution may be generated in advance during the production process. An example is provided regarding the overuse of raw materials, excessive depletion of equipment caused by the production uncertainty as well as the risk brought by stocking special merchandises. Subramanian et al. [18] addressed an analysis on firm's gaming behavior against the emission reduction investment and trading strategies on production policies in carbon trading market under an auctioning mechanism. The result shows that the impact of different quotas (that is more like the "cap" of this paper) on high polluting industries is less than it functions on low types. Besides, firm's efforts on emission reduction will decrease as the industrial pollution increases. Furthermore, the environmental protection activities may be able to provide a larger profit to low polluting industries. The author highlighted the discussion on the interaction between firms rather than putting interest on the operation details of the firm. Gong and Zhou [19] employed a stochastic dynamic optimization model to discuss company's multiperiod production strategy incorporating with the selection of clean or nonclean production technology under the cap-and-trade system. The firm is modeled to decide whether to sell or purchase the quota at the end of each period, which will sequentially influence the quota of the next cycle. The emission volume is assumed to be directly calculated by inventory level which is positively affected by production. The difference from our paper is that we only consider a single period but devote more interests to the firm's specific dynamic strategy rather than a binary decision-making problem. The continuous model we used here is more adaptive in some particular industries such as the production of fluid or small particle products. Carmona et al. [20] studied a multicompany decision-making problem in which the firms need to choose the clean or nonclean technology to optimally arrange their production strategies over a finite period. Different from the paper in which the demand is assumed to be unelastic, we in the current research assume it to be dependent on inventory level. For a single company, Baker and Urban [21] found that customer's consuming behavior will be affected by the size of the displayed goods on shelves; namely, a higher inventory level of the retailers may generate a larger demand. 
Urban [22] developed an inventory management model with inventory-dependent demand while putting forward some advices on the application of such a model. In the analysis, the assumption of 0 -end-point inventory level from the previous research is relaxed. The author realized that since the demand is bounded with the storage goods, an appropriate inventory level at the end of the planning horizon may generate a larger profit. Following the above logic, we in this study have no specific requirement on value of the endpoint inventory level. Furthermore, a more practical problem comes out as follows: how to maximize the total profit over the planning horizon in spite of the end-point inventory level? We believe that the optimal control model is much more suitable for handling this problem. Urban [23] provided a literature review with some suggestions on the inventorydependent demand: this kind of demand can be divided into two categories, of which one is supposed to be connected with initial inventory level and the other is assumed to be variable on the current stock. It is obvious that the studies on the application of dynamic control model with the introduction of stock-dependent demand have been well developed; few of them have considered the environmental performance incorporating with the inventory management activity. In this paper, we take into account the energy consumption in inventory management activity, which will further generate carbon emission. The introduction of both inventory- and production-dependent emission models can be extended into retailer operation since we can set productivity to zero for that case.

\section{Problems and Assumptions}

We consider a manufacturing enterprise ready for implementing the cap-and-trade system. Before going into the monitoring period (namely, a period in which the operation process is open to the third party consultant for measuring the emission quantity), the company will receive a freely delivered emission quota, that is, the cap from the government. During this period, if the emission generated from both the production and inventory operation process exceeds the cap, the excessive volume is required (by the government) to be purchased. On the contrary, if the emission is lower than the cap, the company then has the right to sell the difference. Since we only look at a single period, the impact of the firm's decision on the cap of next cycle is neglected. We assume that when the company performs better than the cap, it has the motivation to sell the credit on the consideration of the benefit from carbon trading mechanism. The similar setup can be referred to Ramudhin et al. [24] and Diabat and Simchi-Levi [25]. We assume that the price is exogenous and perfectly competitive, and the demand is only dependent on the inventory level. Also, the information on the customers and the stocking number is assumed to be complete. On the whole, our problem is addressed to discuss how a company dynamically determines its optimal production rates over a finite single time period under the cap-and-trade mechanism with respect to two dependencies-the emission on both the production output and inventory volume and the demand on inventory level. The operating scenario with the carbon footprint is simply depicted in Figure 1.

\section{Models and Analysis}

4.1. Notations. The following parameters and variables are used in the definitions and mathematical models.

\subsubsection{Indices}

$t$ : Time index

$T$ : Length of planning horizon.

\subsubsection{State and Control Variables}

$I(t)$ is the inventory level at time $t$ that is state variable. We assume that $I(0)>0$, which means that the firm has a nonzero initial inventory level.

$x(t)$ is the carbon emission stock at time $t$. We assume that $x(0)>0$, which implies that the firm starts its business before the cap-and-trade system is launched.

$p(t)$ is the market price of the product that is the function of time $t$ that is assumed to be independent of company's behaviour.

$d(t)$ is the demand rate at time $t$. In this paper, it is essentially the function of inventory level, that is, $d(t)=d(I(t))$, and we assume that $\partial d(I(t)) / \partial I>0$.

$r(t)$ is the production rate at time $t$ that is the unique control variable in this paper.

$f(r(t))$ is the production cost at time $t$ that is assumed to be a convex function of production rate; that is, $\partial f(r) / \partial r>0, \partial^{2} f(r) / \partial r^{2} \geq 0$ are satisfied.

$c(I(t))$ is the inventory cost at time $t$ that is the function of $I(t)$ and satisfies $d c(I) / d I>0$.

$\bar{x}$ is the emission cap over the whole planning horizon.

$\alpha$ is the emission factor that is assumed to be constant with product unit.

$\beta$ is the emission factor that is constant with inventory unit.

$p_{\mathrm{C}}$ is the carbon price that is assumed to be identical in selling and buying for the simplicity of analysis.

\subsection{Models}

4.2.1. Objective Function. Under a reasonable assumption that planning horizon is relatively short, we use an undiscounted optimal control model for constructing the following objective function where we omit the time index when no confusion arises:

$$
\max : \int_{0}^{T}(p(t) p(I)-c(I)-f(r(t))) d t+p_{\mathrm{C}}(\bar{x}-x(T)) .
$$




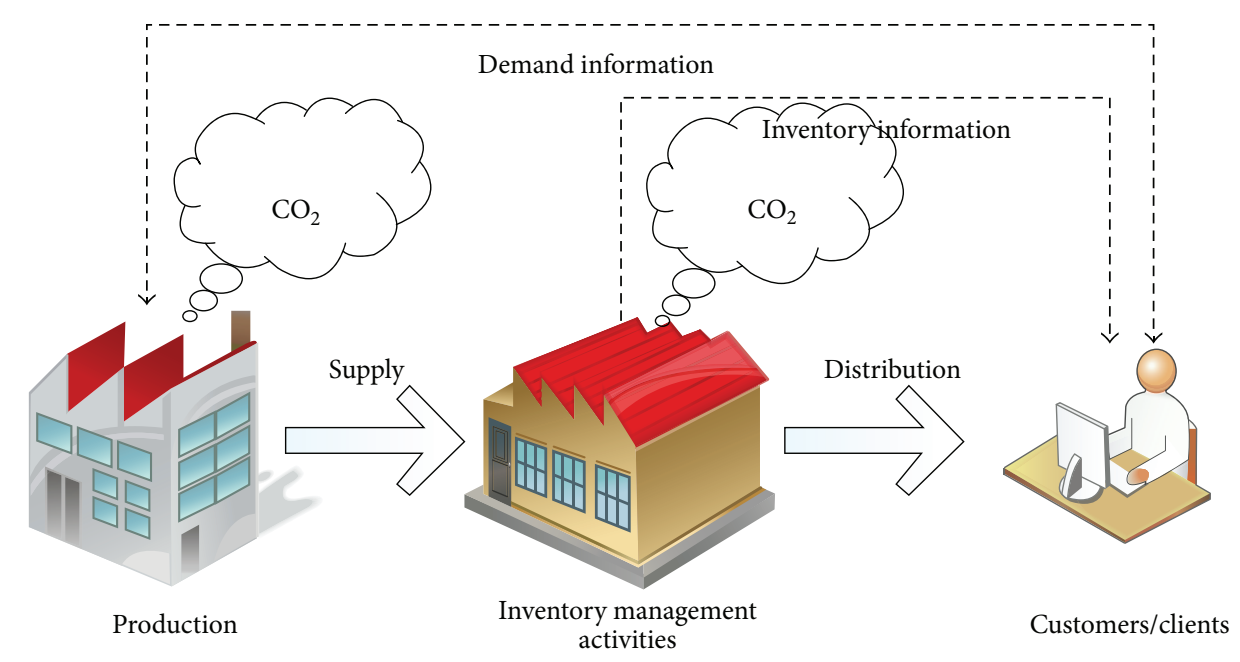

FIGURE 1: A simplified carbon footprint from production to inventory processing.

The function consists of four terms; from left to right, they are sales revenue, inventory holding cost, production cost, and income from carbon trading.

4.2.2. State Equations. The transition function of the inventory level is

$$
\dot{I}(t)=r(t)-d(t)
$$

Let $I_{0}>0$ represent the strictly positive inventory at the time point right before the planning horizon. Consider the following:

$$
\dot{x}(t)=\alpha r(t)+\beta I(t) .
$$

Equation (3) denotes the motion of emission stock (cumulated volume) that equals the weighted sum of production and inventory level. The weights are the corresponding factors which represent the conversion rates, respectively, from the energy consumption of both the production and inventory processing activities to the carbon emission. For example, in practice we can firstly calculate the electricity power consumption and plant transportation fuel consumption per each product unit in both production and inventory management process and then approach the emission factor by tracking the power source. For power consumption, we need to clarify the emission factor of the grid which is dependent on the power generation method, for example, thermal, wind, hydro, nuclear, or weighted sum of some of them. For the transportation, we can directly use the emission factors of gasoline or diesel combustion.

Naturally, the production rate should be nonnegative, and according to the findings of Kamien and Schwartz [26], the differential equation (2) guarantees that $I(t) \geq 0$. Since the initial carbon emission is strictly positive, we have a constantly positive emission stock level $x(t)>0$ over the whole cycle.
4.2.3. The Hamilton. The current value Hamilton with constraints coefficients is

$$
\begin{aligned}
L= & p(t) d(I)-c(I)-f(r(t))+\lambda_{1}(r(t)-d(t)) \\
& +\lambda_{2} \alpha r(t),
\end{aligned}
$$

in which $\lambda_{1}, \lambda_{2}$, respectively, denote the costate functions of the inventory variation and the current emission (i.e., the change of the emission stock).

4.3. Solutions and Analysis. The Euler equations of problem (4) are shown in which we neglect the independent variables with no confusion arising in the following:

$$
\dot{\lambda}_{1}=\lambda_{1}\left(\frac{\partial d}{\partial I}\right)-\beta \lambda_{2}-p\left(\frac{\partial d}{\partial I}\right)+\frac{\partial c}{\partial I}
$$

Since there is no special requirement on the emission quantity at the end point, we have $\lambda_{2}(T)=-p_{C}$; namely, the transversality condition for the inventory costate function is $\lambda_{1}(T)=0$. Accordingly, we have

$$
\dot{\lambda}_{2}=0 .
$$

Because emission is strictly positive and $\lambda_{2}(T)=-p_{\mathrm{C}}$, it can be easily derived that $\lambda_{2}(t)=-p_{\mathrm{C}}<0$ which states that the marginal effect of carbon emission is valued opposite to that of the carbon trading price. The necessary and slackness conditions of the optimal solution are as the following:

$$
\frac{\partial L}{\partial r}=-\frac{\partial f}{\partial r}+\lambda_{1}+\alpha \lambda_{2} \leq 0, \quad r \geq 0, r\left(\frac{\partial L}{\partial r}\right)=0 .
$$

Equation (7) indicates that the marginal production cost (MPC) is equal to the weighted average sum of the marginal effects $\lambda_{1}$ and $\lambda_{2}$ with the weights of 1 and $\alpha$, as the company produces a positive output. On the contrary, if the firm produces nothing, the MPC will be higher because $\partial f / \partial r>$ $\lambda_{1}+\alpha \lambda_{2}$. 
4.3.1. The Specified Function. For further discussion, we tend to specify all the functions as follows.

Let $d(I)=\delta I$ be the demand function, where $\delta$ is assumed to be nonnegative.

Let $c(I(t))=h I$ be the inventory holding cost function that is linear to the inventory level.

Let $f(r)=\theta r^{2}$ be the production cost function in which $\theta$ is assumed to be positive constant.

The specified Lagrangian function with costate variable is as follows (the variable arguments are here and similarly hereinafter omitted if no confusion arises):

$$
L=p \delta I-h I-\theta r^{2}+\lambda_{1}(r-\delta I)+\lambda_{2}(\alpha r+\beta I) .
$$

Replacing the corresponding terms in (5) and (6) with the specified functions, we obtain

$$
\dot{\lambda}_{1}=\lambda_{1} \delta-\beta \lambda_{2}+h-p \delta
$$

where $\lambda_{2}=-p$ is known and also the free-end value of the emission, $\lambda_{1}(T)=0$, is satisfied. The transition function of the inventory costate can be resolved as

$$
\lambda_{1}^{*}(t)=\frac{e^{-T \delta}\left(e^{T \delta}-e^{t \delta}\right)\left(\delta p-\beta p_{\mathrm{C}}-h\right)}{\delta},
$$

which shows that the marginal effect of the inventory variation depends on the sign of $\delta p-\beta p_{C}-h$. Evidently, when the product price increases, the increment of the inventory could be beneficial to the firm's profit, but when the carbon transaction price or the $\mathrm{MHC}$ increases, retaining a larger number of stock would not be encouraged.

4.3.2. Unconstrained Solution. According to the F.O.C, the unconstrained optimal production trajectory can be worked out as the following formulations (sufficient condition is evidently satisfied; thus, the proof is omitted). The corresponding inventory and emission strategy trajectories are derived by (11)' and (11) $)^{\prime \prime}$ as follows:

$$
\begin{aligned}
r^{*}(t)= & \frac{\left(e^{-T \delta}\left(e^{T \delta}-e^{-t \delta}\right)\left(p \delta-\beta p_{\mathrm{C}}-h\right)-\delta \alpha p_{\mathrm{C}}\right)}{2 \theta \delta}, \\
I^{*}(t)= & \left(\frac{1}{4 \delta^{2} \theta}\right) e^{-(1+T) \delta} \\
& \times\left(\left(e^{t \delta}-1\right)\left(1+e^{t \delta}-2 e^{T \delta}\right) h\right. \\
& +\left(e^{t \delta}-1\right) p_{\mathrm{C}}\left(\left(1+e^{t \delta}-2 e^{T \delta}\right) \beta-2 e^{T \delta} \alpha \delta\right) \\
& \left.+\delta\left(4 e^{T \delta} \delta \theta I_{0}-\left(e^{t \delta}-1\right)\left(1+e^{t \delta}-2 e^{T \delta}\right) p\right)\right),
\end{aligned}
$$

$x^{*}(t)$

$$
\begin{gathered}
=\left(\frac{1}{4 \delta^{3} \theta}\right) e^{-(t+T) \delta} \\
\times\left(h \left(2 e^{t \delta} \alpha \delta\left(e^{t \delta}-e^{T \delta} t \delta-1\right)\right.\right. \\
\left.+\beta\left(1-2 e^{t \delta}+e^{2 t \delta}-2 e^{T \delta}+e^{(t+T) \delta}(2-2 t \delta)\right)\right) \\
+p_{\mathrm{C}}\left(-2 e^{(t+T) \delta} t \alpha^{2} \delta^{3}\right. \\
-2 \alpha \beta \delta\left(e^{t \delta}-e^{2 t \delta}+e^{T \delta}\right. \\
\left.+e^{(t+T) \delta}(-1+2 t \delta)\right) \\
+\beta^{2}\left(1-2 e^{t \delta}+e^{2 t \delta}-2 e^{T \delta}\right. \\
\left.\left.+e^{(t+T) \delta}(2-2 t \delta)\right)\right) \\
+\delta\left(-p\left(2 e^{t \delta} \alpha \delta\left(e^{t \delta}-e^{T \delta} t \delta-1\right)\right.\right. \\
+\beta\left(1-2 e^{t \delta}+e^{2 t \delta}-2 e^{T \delta}\right. \\
\left.\left.+e^{(t+T) \delta}(2-2 t \delta)\right)\right) \\
\left.\left.+4 e^{T \delta} \delta\left(\left(e^{t \delta}-1\right) \beta I_{0}+e^{t \delta} \delta x_{0}\right) \theta\right)\right) .
\end{gathered}
$$

From (11), we obtain the following observations: given that the other conditions fixed (1), the output decreases with time passing; (2) the current production rate should be decreased as the carbon price increases. From the firstorder derivative of $r^{*}(t)$ on $p_{\mathrm{C}}$, we can easily find that if $\alpha<\left(e^{(t-T) \delta}-1\right) \beta / \delta$, the production output is increased with $p_{\mathrm{C}}$, but if $\alpha>\left(e^{(t-T) \delta}-1\right) \beta / \delta$ and also $\alpha>0$, only the latter condition can be satisfied. It implies that, for the company, operating within the cap-and-trade market should be more profitable; (3) intuitively, the output is increasing with either the product price or the MHC; (4) it can be analytically reached that if the emission from the inventory process is not involved in the model, that is, $\beta=0$, the current production rate would be higher, because we have $\partial r(t) / \partial \beta=e^{-T \delta}\left(e^{t \delta}-\right.$ $\left.e^{T \delta}\right) p_{\mathrm{C}} / 2 \delta \theta$; (5) if $p_{\mathrm{C}}=0, \beta=0$, and also $\alpha=0$, the output would be higher than that of (4), and actually in this situation, the firm has not participated in the carbon transaction.

4.3.3. Optimal Solution with Capacity Constraint. Consider the capacity constraint $0 \leq r(t) \leq r_{\max }$ for each time period; the objective function is the following:

$$
L=-\theta r^{2}+\left(\lambda_{1}+\lambda_{2} \alpha\right) r+\lambda_{2} \beta I+p(M+\delta I)-h I-\lambda_{1} \delta I .
$$

Using the Pontryagin maximum principle, the constrained optimal solution can be constructed as follows:

$$
r^{*}(t)= \begin{cases}0 & \text { if } \lambda_{1}+\lambda_{2} \alpha \leq 0 \\ \frac{\left(\lambda_{1}+\lambda_{2} \alpha\right)}{2 \theta} & \text { if } 0 \leq \lambda_{1}+\lambda_{2} \alpha \leq 2 \theta r_{\max } \\ r_{\max } & \text { if } 2 \theta r_{\max } \leq \lambda_{1}+\alpha \lambda_{2} .\end{cases}
$$


4.3.4. Constrained Optimal Decision Policies. In the following parts, firstly, we assume the existence of each productivity level at the beginning of the decision duration period and then solve the subsequent part of the whole corresponding optimal policy. Secondly, based on the derived dynamic strategy, we try to explore the start and end points of different duration intervals with different production rate. Then, the impact of some factors on the length of the duration period is discussed.

(1) Idling Capacity. Idling means that the firm stops producing any products.

(a) State Equation. Obviously, when $r^{*}(t)=0$ is satisfied, the inventory will decline with the passing time with the speed of the demand rate. The dynamics is $I_{1}^{*}(t)=e^{-t \delta} I_{10}$ in which $I_{10}>0$ denotes the initial inventory level of a certain 0 -production-rate period and it does not need to meet the condition of $I_{10}=I_{0}$. The corresponding carbon emission path is $x_{1}^{*}(t)=\left(\left(1-e^{-t \delta}\right) \beta I_{0}+\delta x_{0}\right) / \delta$. The subscripts of $I_{1}^{*}(t), x_{1}^{*}(t)$, and $I_{10}$ are used for differentiating the decision stages but are irrelevant to the decision-making order.

(b) Decision Duration Interval. From the costate equations, Proposition 1 follows.

Proposition 1. Once the firm stops production at $t_{1} \in[0, T)$, the decision should last until the end of the planning horizon. (Here and similarly hereinafter the subscript of time index is only used for identifying the analysis sequence but is irrelevant to the real decision-making orders.) See the proof in Appendix A.

(1) Intermediate Production Rate. In this situation, the company neither shut down its machine, nor run out of its capacity.

(a) State Equation. In this case, the form of the inventory or the emission trajectories is similar to $(11)^{\prime}$ and $(11)^{\prime \prime}$, respectively, so we will not repeat the description.

(b) Decision Duration Interval. Suppose that the firm is to implement the intermediate production rate in the planning horizon; then, the following proposition can be derived.

Proposition 2. At a time point of $t_{2} \in[0, T)$, once the intermediate production rate is launched, it will last until the end of the cycle unless a 0 -production-decision period is reached. The switching time between the above two strategies is $t_{2}=\left(\log \left[e^{T \delta}\left(1+\alpha \delta p_{C} /\left(h-\delta p+\beta p_{C}\right)\right)\right]\right) / \delta$. See the proof in Appendix B. Next, we analyze the impact of $p_{C}$ and $p$ on the length of the decision duration period mentioned above, and then Lemma 3 can be derived.

Lemma 3. Based on the decisions of the intermediate and 0 production rates, in the range of the real number, when $h-p \delta>$ $0, \underline{t}_{2}$ will increase with either $p_{C}$ or $p$, and if $h-p \delta<0, \underline{t}_{2}$ will increase with $p$ but decrease when $p_{C}$ increases; when $h-\delta p+$ $\beta p_{C}<-\alpha \delta p_{C}, t_{2}$ will decrease when $p_{C}$ rises. See the proof in Appendix $B$.
From Lemma 3, what is worthy of remarking is that as we fix the initial time of the duration interval incorporating with the intermediate production rate, the growth of $t_{2}$ will extend such time period. Yet if before that there existed a duration time period in which the company uses its maximum capacity, the length of that time period will be dependent on the end timing of the maximum production rate period. For this problem, we will present a quantitative discussion in Section 5.

(1) Maximum Production Rate. In this case, the company will use its whole capacity.

(a) State Equation. Substituting $r^{*}(t)=r_{\max }$ in to (2), we obtain $I_{3}^{*}(t)=e^{-t \delta} I_{30}+r_{\max }\left(1-e^{-t \delta}\right) / \delta$ which will generate a difference of $\Delta I_{1-3}^{*}(t)=r_{\max }\left(1-e^{-t \delta}\right) / \delta$ under a parallel comparison with 0 -production-decision path at each time point. Besides that the $\Delta I_{1-3}^{*}(t)$ will be enlarged by $e^{-t \delta} r_{\max }$ which will increase with the maximum capacity. The corresponding dynamics of the carbon emission is $x_{3}^{*}(t)=\left(\delta\left(\left(1-e^{-t \delta}\right) \beta I_{30}+\right.\right.$ $\left.\left.\delta x_{30}+t(\beta+a \delta) r_{\max }\right)+\left(e^{-t \delta}-1\right) \beta r_{\max }\right) / \delta^{2}$.

(b) Decision Duration Interval. Obviously, from the above propositions, the maximum production rate, if necessary, should be implemented at the beginning of the cycle. Following this, Proposition 4 can be further derived.

Proposition 4. If the firm implements the maximum production rate at the initial time of the planning horizon, the production trajectory will be nonincreasing until the end unless it meets the intermediate production rate. Accordingly, the switching time is $\bar{t}_{3}=\log \left[e^{T \delta}\left(1+\delta\left(\alpha p_{C}+2 r_{\max } \theta\right) /(h-\delta p+\right.\right.$ $\left.\left.\left.\beta p_{C}\right)\right)\right] / \delta$. See the proof in Appendix C. From Proposition 4 follows Lemma 5.

Lemma 5. If there exist two duration periods with, respectively, maximum and intermediate production rate decisions through the planning horizon, over the range of the real number, when $h-\delta p+\beta p_{C}>0$ and $\alpha h-\alpha \delta p-2 \beta \theta r_{\max }>0, \bar{t}_{3}$ will increase with $p_{C}$ or $p$. If $\alpha h-\alpha \delta p-2 \beta \theta r_{\max }<0, \bar{t}_{3}$ will still increase with $p$ but decrease with the increment of $p_{C}$; when $h-\delta p+\beta p_{C}<$ $-\alpha \delta p-2 \beta \theta r_{\max }$, we will reach the identical result as the above. The proof is similar to that of Lemma 3; thus, we omit it here.

We make a summary in view of both the above propositions and lemmas and also succinctly list the impact of and on the decision-switching timing in Table 1.

In this part, we briefly analyze the influences of the other parameters on the switching times. The derivative of $\partial \bar{t}_{3} /\left.\partial \alpha\right|_{h+\beta p_{\mathrm{C}}-p \delta<-\alpha \delta p_{\mathrm{C}}-2 \delta \theta r_{\max }}<0$ states that the firm will terminate the maximum production rate duration period in an earlier time when the emission factor of either the production or stocking process becomes higher; $\partial \underline{t}_{2} /\left.\partial \alpha\right|_{h+p \beta c-p \delta<-p c \alpha \delta}<$ 0 indicates that the idling production interval will be shortened if the production emission factor is increasing. This may provide some constructive suggestions on the firm's production policies about the choice regarding different production resources of different energy consumption levels; moreover, we find that the cross partial derivative of $\underline{t}_{2}$ or 
TABle 1: The impact of and on the "max-mid" and "mid-0" switching timing.

\begin{tabular}{lc}
\hline Conditions & Effects on $\underline{t}_{2}$ \\
\hline$h-\delta p+\beta p_{\mathrm{C}}>0$ and $h-\delta p>0$ & increases $p_{\mathrm{C}}$ or $p$ \\
or $h-\delta p<0$ & decreases when $p_{\mathrm{C}}$ increases \\
$h-\delta p+\beta p_{\mathrm{C}}<-\alpha \delta p_{\mathrm{C}}$ & and increases with $p$ \\
\hline Conditions & Effects on $\bar{t}_{3}$ \\
\hline$h-\delta p+\beta p_{\mathrm{C}}>0$ and $\alpha h-\alpha \delta p-2 \beta \theta r_{\max }>0$ & increases $p_{\mathrm{C}}$ or $p$ \\
or $\alpha h-\alpha \delta p-2 \beta \theta r_{\max }<0$ & decreases when $p_{\mathrm{C}}$ increases \\
$h-\delta p+\beta p_{\mathrm{C}}<-\alpha \delta p-2 \beta \theta r_{\max }$ & and increases with $p$ \\
\hline
\end{tabular}

$\bar{t}_{3}$ on $\beta$ and $p$ or $p_{\mathrm{C}}$ is negative, which means that the increasing inventory energy consumption level may negatively affect the influence of product or carbon trading price on the decision interval. One should also recognize that if $\partial \bar{t}_{3} /\left.\partial \alpha\right|_{h-\delta p+\beta p_{C}<-\alpha \delta p-2 \beta \theta r_{\max }}<0$, a higher production cost factor encourages the firm to shorten the length of its maximum production rate duration time. From the above, comparing with the results derived from the functions of general form, we conclude that, in a dynamic environment, the firm's control on the production rate mainly functions at the length of different decision intervals rather than the current production rate.

\section{Numerical Analysis}

As an example, suppose that the value of the parameters is as follows:

$$
\begin{aligned}
& T=12, I_{0}=1000, p(t)=100, \alpha=2, \beta=0.5, \delta=0.2 \\
& \theta=0.5, h=5, x_{0}=500, \bar{x}=20000, p_{\mathrm{C}}=10, \text { and } \\
& r_{\max }=20
\end{aligned}
$$

5.1. Incapacitated Optimal Solutions. We present a comparative analysis on the optimal dynamic policies of production, inventory, and profit with or without the implementation of the cap-and-trade mechanism. The results without capacity constraint are graphically described in Figures 2, 3, and 4. They illustrate that the emission level over the whole planning horizon is lower in the cap-and-trade system. Figure 5 shows that the emission dynamics under optimal incapacitated production policy will increase with an increasing margin.

5.2. Optimal Solutions with Capacity Constraint. The optimal production policy with capacity constraint is shown in Figure 6 in which the dashed line represents the productivity upper limit $r_{\max }$ and the dotted line represents the idling production.

In the examples, the intersection points of the unconstrained optimal production curve and the productivity limit lines are $t_{2}$ and $\bar{t}_{3}$, respectively. Based on Propositions 2 and 4 , we figure out that $\bar{t}_{3}=3.9528$ and $\underline{t}_{2}=9.4459$. Figure 7 provides us with a general picture regarding the impact of changes in $p_{C}$ on the firm's overall output level through the whole planning horizon. The result shows that the firm's overall output level will decrease as the carbon price increases. In the following, we discuss the impact of $p$ and $p_{C}$ on the

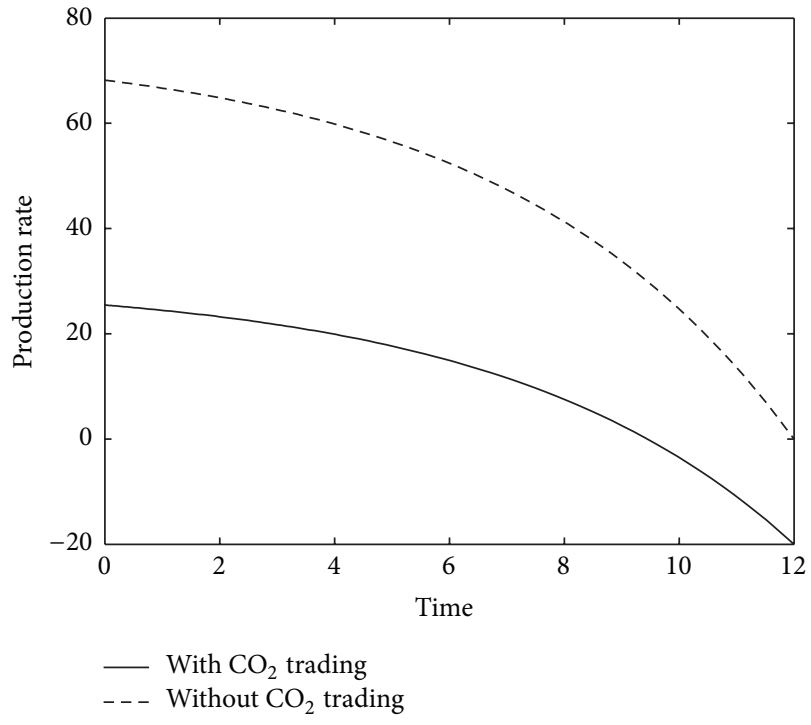

FIGURE 2: Unconstrained optimal production.

lengths of different decision intervals consisting of different production rate decisions as well as the corresponding profit and emission.

According to Table 1 , because $h-\delta p+\beta p_{\mathrm{C}}=-10<$ $-\alpha \delta p_{\mathrm{C}}=-4, \underline{t}_{2}$ will rise with $p$ and decrease with the increment of $p_{C}$. Based on the conditions, when we fix $p=$ $100, p_{\mathrm{C}}<16.6667$ will be satisfied, and when $p_{\mathrm{C}}=10$ is fixed, there will be $p>70$. From $h-\delta p+\beta p_{\mathrm{C}}<-\alpha \delta p-2 \beta \theta r_{\max }=$ $-8, \bar{t}_{3}$ will also decrease when $p_{C}$ increases, but it will increase with $p$ when both the carbon price and product price are within some certain ranges as $p_{\mathrm{C}}<12.2222, p>90$. Fix $p=100$ and set $p_{\mathrm{C}} \in[0,12]$ to carry out a similar analysis; the results are depicted in Figures 8 and 9. By the comparison, we recognize that since the decreasing margin of $t_{2}$ is larger than that of $\bar{t}_{3}$, for the firm, in the face of a climbing carbon price, the decreasing margin of the interval with maximum production rate should be larger than that of the interval with middle production rate. Besides, the negative part of the curve in Figure 9 implies that the firm may have already commenced to implement the maximum production rate strategy. Through the whole planning horizon, the output will gradually decrease when time passes, and the idling production interval will be extended. Take $p_{\mathrm{C}}=10$ and analyze the impact of $p \in[100,150]$ on $\underline{t}_{2}$ and $\bar{t}_{3}$, drawing 


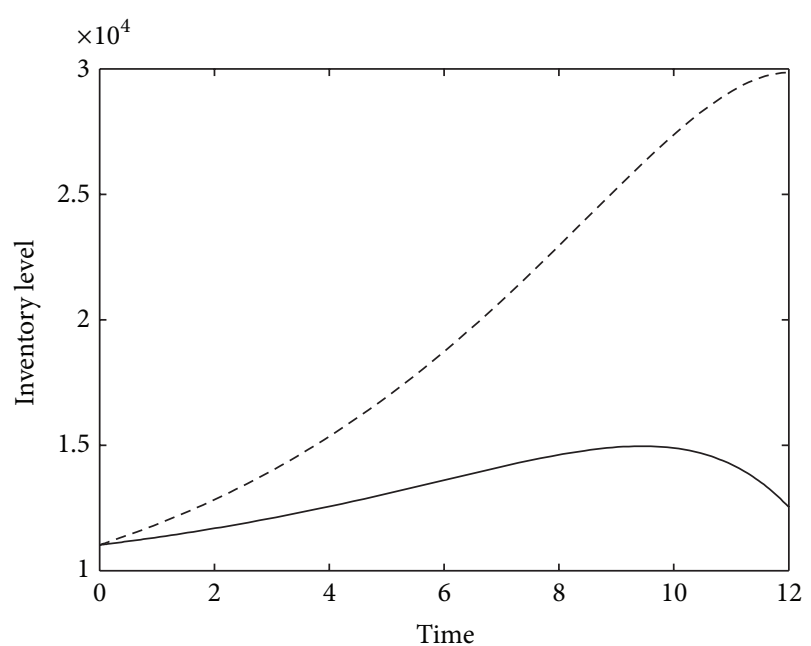

With $\mathrm{CO}_{2}$ trading

-. - Without $\mathrm{CO}_{2}$ trading

FIGURE 3: Unconstrained optimal inventory.

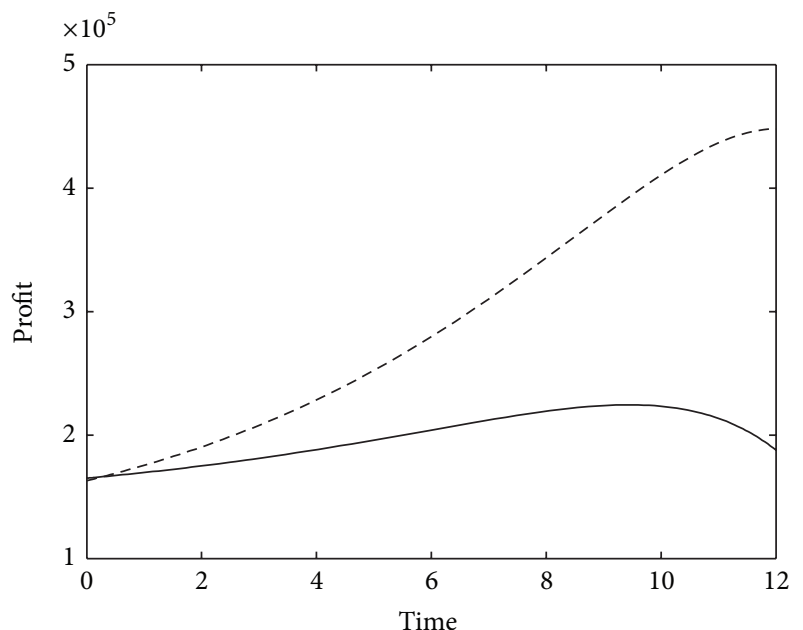

- With $\mathrm{CO}_{2}$ trading

- - Without $\mathrm{CO}_{2}$ trading

FIgURE 4: Unconstrained optimal profit.

the results in Figures 10 and 11, respectively, we find that, in the same range of the product price, $\bar{t}_{3}$ performs more sensitively than $\underline{t}_{2}$ against the variation of $p$. It can be evidently seen that as the price increases, the firm will prolong the decision interval which incorporates with the maximum production rate and simultaneously shorten the idling productivity interval. Looking at the relative motions of $\bar{t}_{3}$ and $t_{2}$, the decision interval with the intermediate production rate is shortened.

In addition, we have the interest on the combined influence of $p_{C}$ and $p$ on $\bar{t}_{3}$ and $t_{2}$. The surface is, respectively, drawn in Figures 12 and 13. The results show that each of the surfaces displays a convex increasing trend, but, besides that, $\underline{t}_{2}$ 's behavior seems to be more evident than $\bar{t}_{3}$ 's. Further, from Figure 12 , as $p$ increases and $p_{C}$ decreases, $\bar{t}_{3}$ will increase

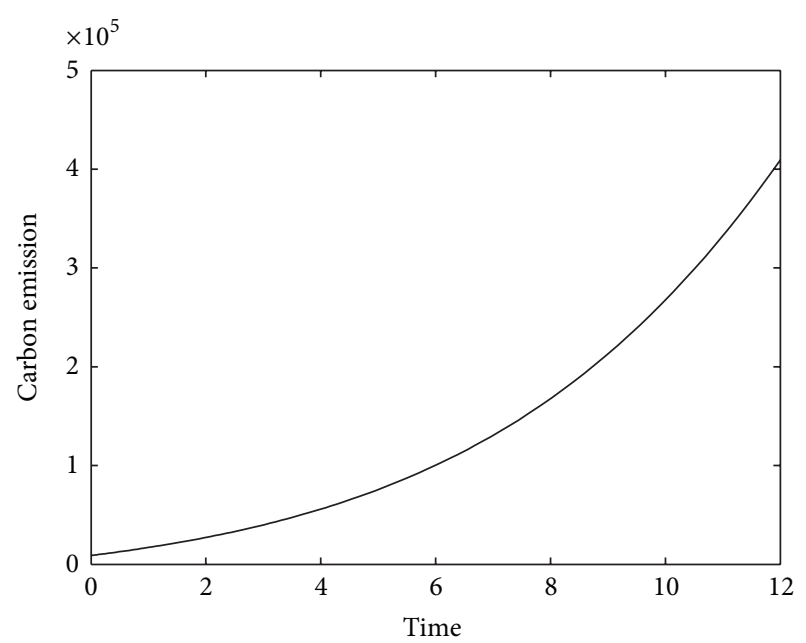

FIgURE 5: Unconstrained optimal emission.

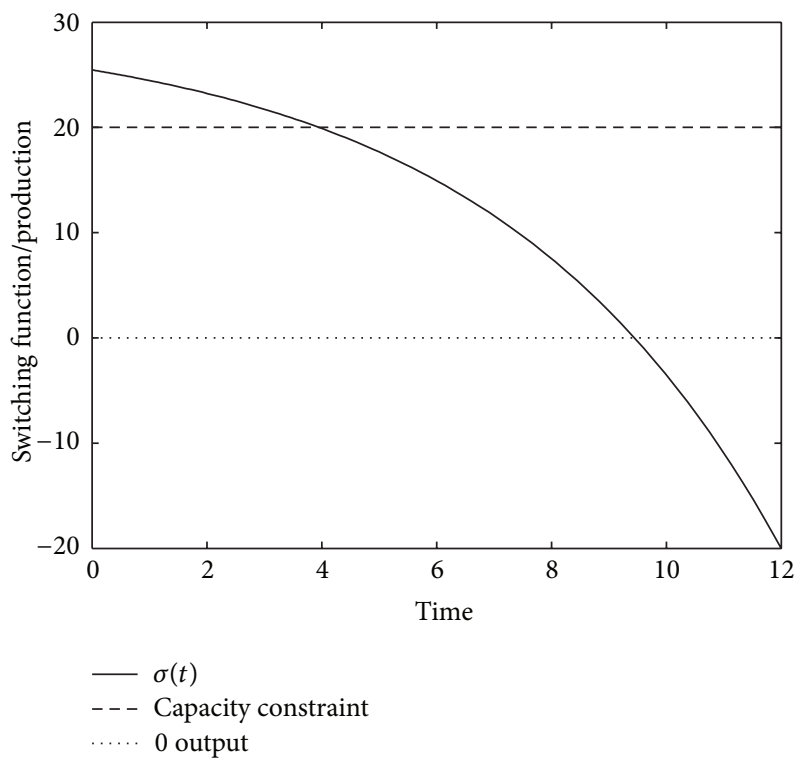

FIgURE 6: Constrained optimal production.

but will sometimes meet an upper bound. However, when observing Figure 13, in the same range of $p$ and $p_{C}$, the upper limit of $t_{2}$ seems not to be so clear.

With respect to the capacity constraint, we firstly fix $p$ to be unchanged and then observe the dynamics of $t_{2}$ and $\bar{t}_{3}$ based on the movement of $p_{\mathrm{C}}$. The corresponding total emission and profit levels of the whole cycle are listed in Table 2. Subsequently, we use the identical logic to detect the variation of $t_{2}$ and $\bar{t}_{3}$ and the variation of the total emission and profit levels in an acceptable range of $p$ drawing the results in Table 3 . Table 2 demonstrates that either the corporate profit or the low-carbon performance will increase with the carbon price. Further, when $p_{\mathrm{C}}$ is approaching 12, even though the firm has stopped using its whole capacity, it is still able to harvest a good repayment because, in this situation, the firm is not only able to gain a lot from a 
TABLE 2: The influence of $p_{\mathrm{C}}$ on $\underline{t}_{2}, \bar{t}_{3}$, the corresponding total profit and emission.

\begin{tabular}{lccccccc}
\hline$p_{\mathrm{C}}$ & $\underline{t}_{2}$ & $\bar{t}_{3}$ & Profit 1 & Profit 2 & Profit 3 & Total profit & Total emission \\
\hline 2 & 9.9007 & 11.7058 & 71052.5411 & 464750.3731 & 7386.3529 & 543189.2671 & 681851.6456 \\
4 & 9.1827 & 11.3433 & 68680.1777 & 456929.9455 & 14217.7865 & 539827.9097 & 614259.1070 \\
6 & 8.1893 & 10.8843 & 65024.3867 & 458889.8609 & 20751.9190 & 544666.1667 & 531603.8175 \\
8 & 6.6855 & 10.2811 & 58465.2367 & 493962.5834 & 28183.0215 & 580610.8416 & 432293.0179 \\
10 & 3.9528 & 9.4459 & 42021.2668 & 696192.3021 & 43280.1076 & 781493.6765 & 314239.1043 \\
12 & $0(-7.0333)$ & 8.1893 & 0 & 796190.4545 & 57880.5879 & 854071.0424 & 168904.8734 \\
\hline
\end{tabular}

In the above table, profit 1 represents the first decision interval, that is, the duration period of maximum production rate; profit 2 represents the intermediate production rate duration period; and profit 3 represents the idling period. Besides, the carbon trading income (or payment) at the end of the cycle is neglected.

TABLE 3: The influence of $p$ on $\underline{t}_{2}, \bar{t}_{3}$, the corresponding total profit and emission.

\begin{tabular}{|c|c|c|c|c|c|c|c|c|}
\hline $\mathrm{CO}_{2}$ trading & $p$ & $t_{2}$ & $\bar{t}_{3}$ & Profit 1 & Profit 2 & Profit 3 & Total profit & Total emission \\
\hline $\mathrm{Y}$ & 100 & 3.9528 & 9.4459 & 42021.2668 & 696192.3021 & 43280.1076 & 781493.6765 & 314239.1043 \\
\hline $\mathrm{N}$ & & & & 42021.2668 & 1227904.4242 & 94318.5298 & 1364244.2208 & \\
\hline Y & 110 & 6.5069 & 9.9727 & 65440.4192 & 529219.0797 & 37970.0436 & 632629.5425 & 417412.6549 \\
\hline $\mathrm{N}$ & & & & 65440.4192 & 1055021.9671 & 85907.2818 & 1206369.6681 & \\
\hline Y & 120 & 7.7635 & 10.3170 & 80599.6796 & 520452.1540 & 39543.7197 & 640595.5533 & 502665.7935 \\
\hline $\mathrm{N}$ & & & & 80599.6796 & 1028252.7208 & 85173.0471 & 1194025.4475 & \\
\hline $\mathrm{Y}$ & 130 & 8.5343 & 10.5616 & 93569.6000 & 544656.4036 & 42753.6183 & 680979.6218 & 576702.9971 \\
\hline $\mathrm{N}$ & & & & 93569.6000 & 1035415.6048 & 86618.7403 & 1215603.9450 & \\
\hline $\mathrm{Y}$ & 140 & 9.0611 & 10.7434 & 105627.6679 & 580551.5702 & 46966.2625 & 733145.5006 & 643189.2194 \\
\hline $\mathrm{N}$ & & & & 105627.6679 & 1056741.4175 & 89068.0487 & 1251437.1341 & \\
\hline $\mathrm{Y}$ & 150 & 9.4459 & 10.8843 & 117216.0494 & 621810.6038 & 50700.2454 & 789726.8986 & 704027.5933 \\
\hline $\mathrm{N}$ & & & & 117216.0494 & 1085813.6561 & 92072.8136 & 1295102.5191 & \\
\hline
\end{tabular}

$\mathrm{Y}$ denotes the situation in which the firm has joined the carbon trading system and $\mathrm{N}$ otherwise. Also $p_{\mathrm{C}}(\bar{x}-x(t))$ is omitted here.

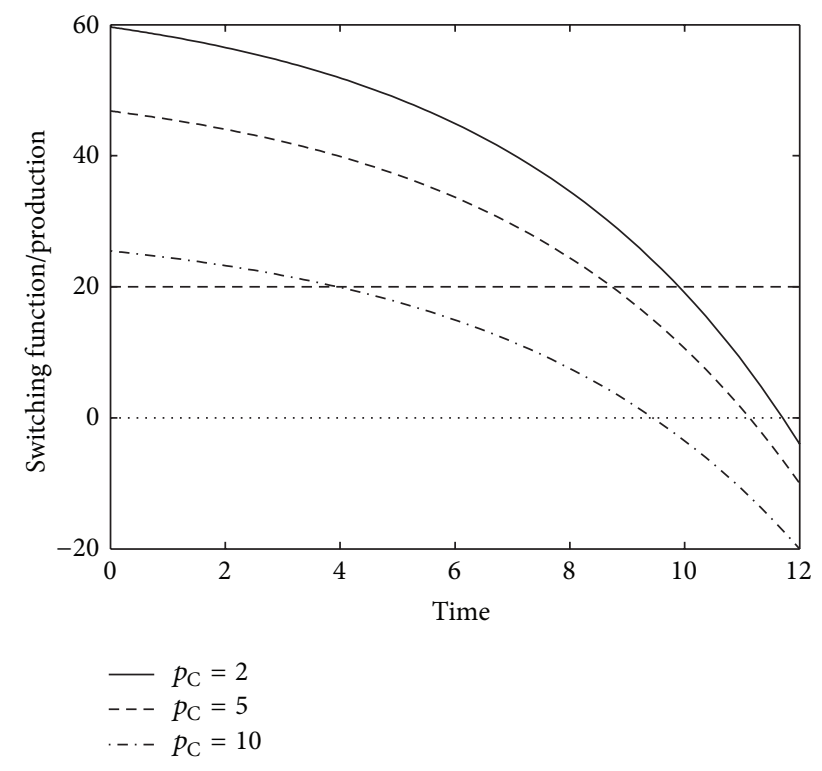

Figure 7: Constrained production paths with different $p_{C}$.

higher carbon transaction price, but it also benefits from the low cost level. From each of the decision-making stages, the profit from the maximum production rate period will decrease when the carbon trading price increases. But the

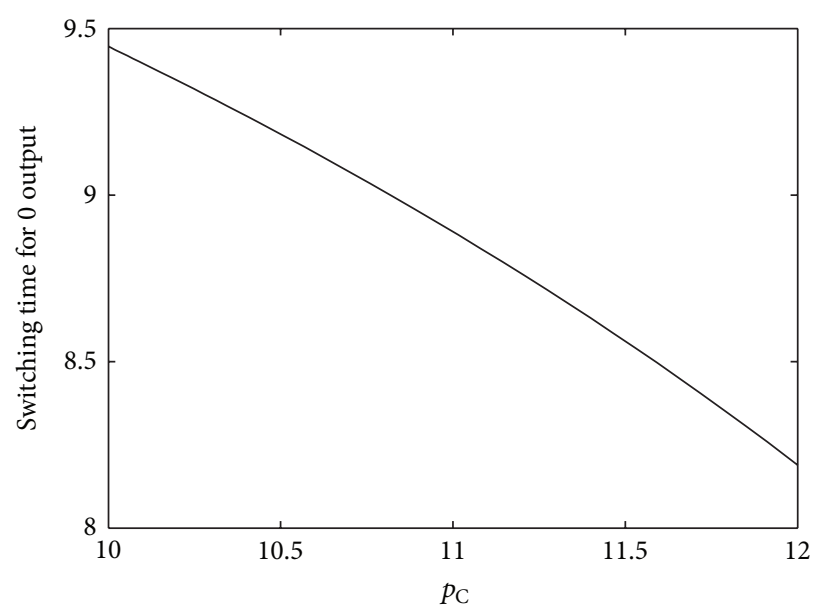

FIgURE 8: The effect of $p_{\mathrm{C}}$ on $\underline{t}_{2}$.

profit will increase with $p_{\mathrm{C}}$ when the firm performs a zero or intermediate productivity strategy. It implies that a high profit is unnecessarily correlated with a large production rate.

Table 2 states that, as the product price increases, the period with middle level of production rate will gradually move backward along the trajectory. During this process, the total profit will decline first but rise again later. The reasons mainly lie in the motion of profit over both the idling and 


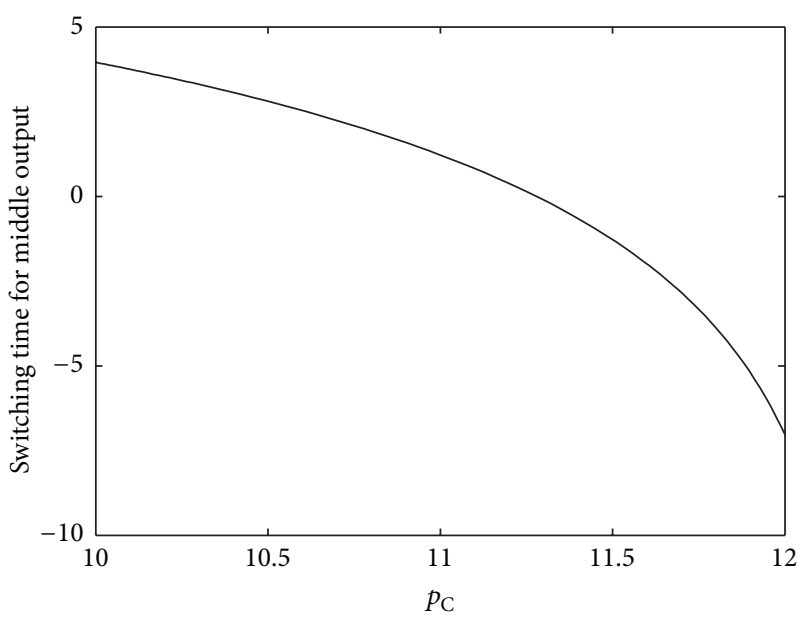

Figure 9: The effect of $p_{\mathrm{C}}$ on $\bar{t}_{3}$.

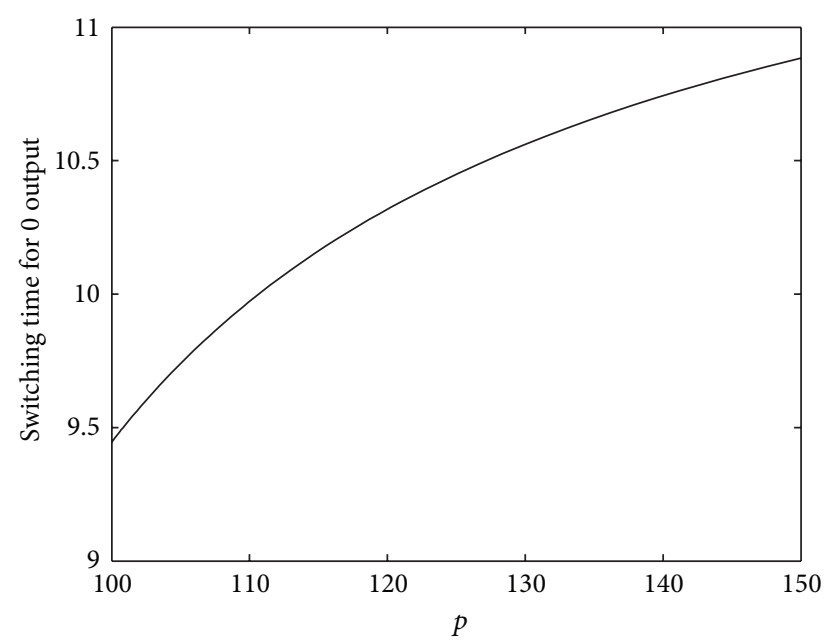

Figure 10: The effect of $p$ on $\underline{t}_{2}$.

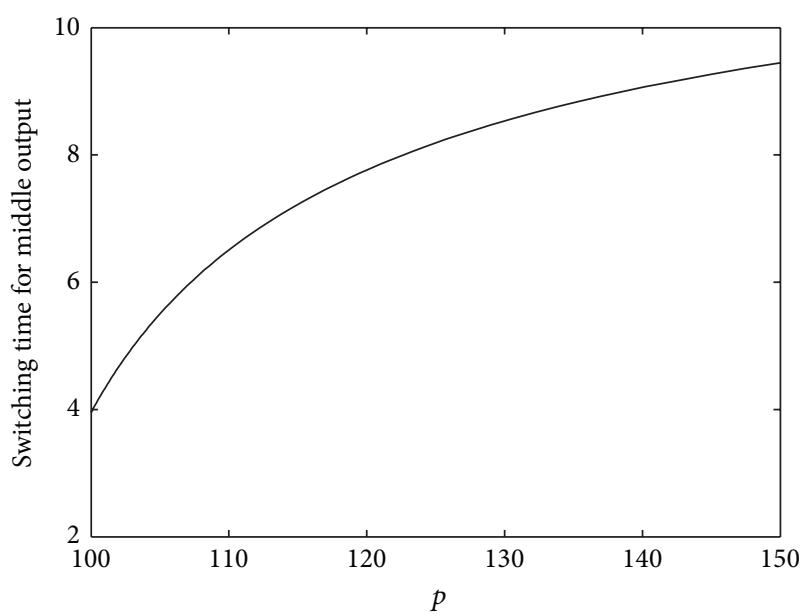

Figure 11: The effect of $p$ on $\bar{t}_{3}$.

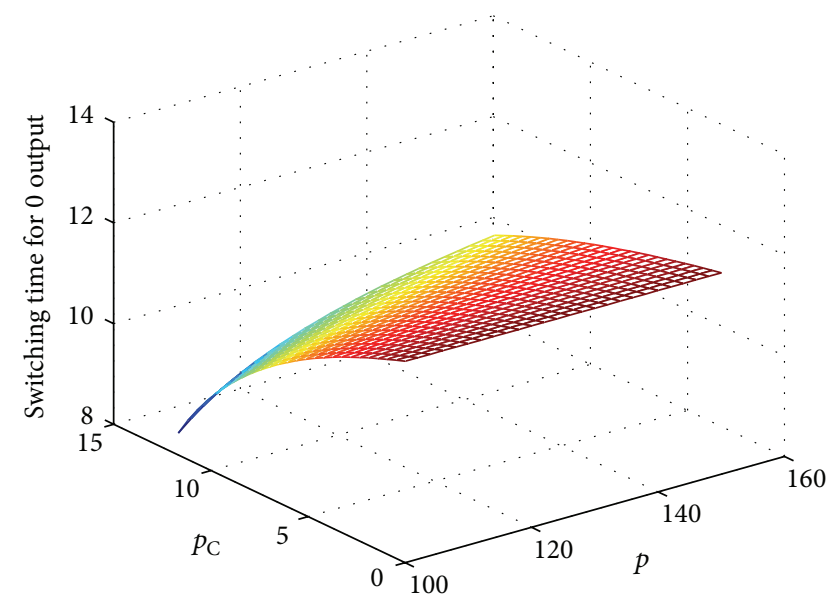

Figure 12: The effect of $p_{\mathrm{C}}$ and $p$ on $\underline{t}_{2}$.

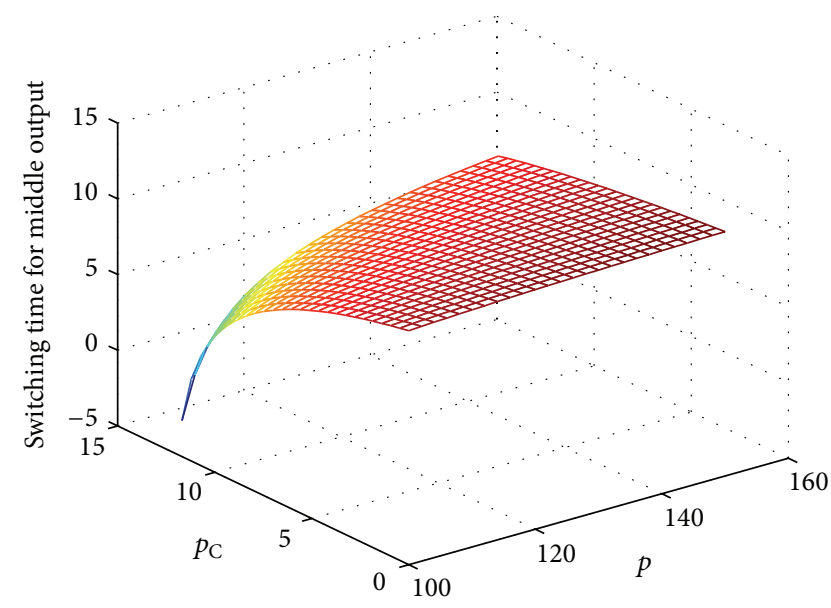

Figure 13: The effect of $p_{\mathrm{C}}$ and $p$ on $\bar{t}_{3}$.

intermediate production rate periods along different output trajectories - they move upward firstly and decline next and then rise again. Due to the extension of the period with maximum production rate, the overall output level is raised. It should be noted that here we do not consider the income or expenditure generated by the carbon trading activity. When we do this, for sure a smaller output would be more favorable to the firm. Furthermore, we find that the carbon trading mechanism will smoothen the profit dynamic trajectories; that is, the difference between each two profit levels from each two particular production paths will become smaller as time passes. Besides, we have also compared the profitability in the two cases with and without the consideration of carbon trading market. The result shows that the total profit is smaller under trading mechanism. Apparently, the profit level seems very sensitive to the quota delivered by the government. If the cap is large enough, the firm will have the potential to promote its revenue by the end of the planning horizon. On the opposite side, however, as receiving a smaller quota, the company needs to either improve the energy consumption 
efficiency, reduce production costs, or promote the product demand and take actions on any other aspects.

\section{Conclusion}

In this paper, considering the inventory-dependent demand and the carbon emission sources from both production and inventory management process, a continuous optimal control model with free end-point value was applied to analyze the optimal dynamic production strategy over a finite time period. Based on the functions of general forms, we have come to an instant result in which the costate of the emission stock equals the opposite value of the carbon trading price. With the slackness condition of the control variable, we have derived that the emission (or energy consumption level) of a high energy consumption enterprise may have a larger impact on its marginal production cost compared to that of the low energy consumption type. Through the analysis on the specified models, we found that the unconstrained optimal decision path reflects the connections between the theoretic optimal production rate, the marginal effect of inventory, the marginal holding cost, the carbon trading price, and so on. For instance, a higher carbon price will make the higher inventory level a disadvantage to the firm's profitability. Through a qualitative analysis, we have realized that either the unconstrained optimal production rate, the inventory volume, or the profit level without carbon-trading mechanism is higher than that within the cap-and-trade market. As for considering the capacity constraint, there are different combination patterns consisting of different production rates along the monotonic and nonincreasing optimal decision trajectory over the planning horizon. As for the problem of when to implement which level of production rate, a series of external factors need to be determined. For this issue, our main contribution lies in two aspects. One is the specific analysis concerning the impact of carbon and product prices on the positions of starting and ending time points of different production rates; the other is a quantitative analysis on the differences of both the total profit and carbon emission under different optimal solutions. The result indicates that a higher carbon price is beneficial not only to the profit, but also to the firm's low-carbon performance. But a relatively lower one may stimulate the firm to adopt some particular production strategies such as smaller emission that can be obtained with the favorable profit. It seems that a gain of both fame and wealth can be gained through the above discussion. It is also realized that, over the whole planning horizon with the capacity limit, the firm will not perform worse at different stages by different production rates without participation in the cap-and-trade system than it does within the mechanism. Naturally, it is obvious for the company that a higher emission quota indicates a larger possibility of benefiting more from carbon trading market. A lower quota however may force the enterprise to carefully consider other methods for reducing the energy consumption. Besides, we have also found that, with a higher production emission factor, the firm will stop the maximum production rate operation at an earlier time point. On the other side, the inventory emission factor will negatively influence the effect of the product and carbon prices on the timing of switching the strategies. Insightfully, the requirement on the emission factors provides some directive suggestions on the firm's decision about how much should be invested into its capacity or how to select the equipment types with different energy consumption levels. To make a summary on the above, we believe that the cap-and-trade mechanism not only provides the enterprise with the opportunities but also brings the challenges. The opportunities mainly lie in the carbon trading system which will directly enhance the firm's transaction income. The challenges come from the disadvantageous situation met by the company under the carbon trading mechanism, since the trend of losing money stimulates the company to find other ways for keeping the profitability.

The contribution of this paper mainly comes from the consideration on the carbon footprint through the company's production and inventory management process, which impels the study on the carbon emission incorporating with the both activities. Even though the energy consumption from production is being widely studied and the stockdependent demand assumption is not uncommon in the existing literatures, we introduced both of them into an environment-friendly production problem. The detailed discussion of the production strategies embedded in the analysis of the optimal control approach provides constructive suggestions on firm's optimal dynamic operations.

The shortcomings of this paper include the following aspects: (1) we added some relatively strong assumptions such as the perfect information about the inventory on the customers; (2) carbon emission has been set linearly related to the production output and inventory level, which could be much simpler than the practical emission monitoring methods; (3) we have only taken into account the cost of increasing both the productivity and inventory level but neither the idling cost of reducing the productivity nor the production setup cost has been considered; (4) optimal control model will clearly exhibit a dynamical picture of the decision-making process, but the imaginary roots within the solutions of the logarithm function made it difficult for us to seek the practical interpretation for the theoretical problems. At this point, the application range of this paper will be subject to some restrictions.

In future research, more commercial and operation activities, such as offsite shipment, assembling, and even technology improvement, could be considered as the control variables; also, more than one firm and their interactions such as competition and collaboration could be included in the model; under multifirm framework, rather than a fixed cap, the effect of the cap delivery patterns on firms' decisionmaking policies is worthy of discussing; moreover, the problem could be addressed under a multiperiod scenario where the strategy should be more complicated, since different cap values will influence the decisions over periods; the dependency between demand and inventory level can also be extended, say between demand and product price; the price function can be considered to be related to other factors but not only limited by time. For the research approach, a discrete optimal control model is expected to be used in a later study, which would be more applicable in other real business cases. 


\section{Appendices}

\section{A. Proof of Proposition 1}

Let $\sigma(t)=\lambda_{1}+\alpha \lambda_{2} e^{-T \delta}\left(e^{T \delta}-e^{t \delta}\right)\left(\delta p-\beta p_{\mathrm{C}}-h\right) / \delta-\alpha p_{\mathrm{C}}$, considering the condition of $\delta p-\beta p_{\mathrm{C}}-h<\delta \alpha e^{T \delta} p_{\mathrm{C}} /\left(e^{T \delta}-\right.$ $\left.e^{t_{1} \delta}\right)$ under which the firm will idle the production rate at time $t_{1}$. Intuitively, $\delta p-\beta p_{\mathrm{C}}-h<\delta \alpha e^{T \delta} p_{\mathrm{C}} /\left(e^{T \delta}-e^{\left(t_{1}+\Delta t\right) \delta}\right)$ is also satisfied when $\Delta t$ is an arbitrarily positive real number on the interval of $\left[0, T-t_{1}\right]$.

\section{B. Proof of Proposition 2}

The condition of implementing the intermediate production rate in $t_{2} \in[0, T)$ is $\delta \alpha e^{T \delta} p_{\mathrm{C}} /\left(e^{T \delta}-e^{t_{2} \delta}\right)<\delta p-\beta p_{\mathrm{C}}-h<$ $\delta e^{T \delta}\left(2 \theta r_{\max }+\alpha p_{\mathrm{C}}\right) /\left(e^{T \delta}-e^{t_{2} \delta}\right)$. Apparently, the first and the last terms are the increasing function of time; thus, as time prompts forward, the second inequality will still hold, but the first part is uncertain. The firm will begin carrying out 0 production at the moment of $t_{2}+\Delta t$ when $\delta p-\beta p_{\mathrm{C}}-h<$ $\delta \alpha e^{T \delta} p_{\mathrm{C}} /\left(e^{T \delta}-e^{\left(t_{2}+\Delta\right) \delta}\right)$ is satisfied. Solving the switching time, $\underline{t}_{2}=\left(\log \left[e^{T \delta}\left(1+\alpha \delta p_{\mathrm{C}} /\left(h-\delta p+\beta p_{\mathrm{C}}\right)\right)\right]\right) / \delta$ can be obtained.

B.1. Proof of Lemma 3. Firstly, we need to ensure that the content that we discuss is restricted in the scope of real number; thus, $h-\delta p+\beta p_{\mathrm{C}}>0$ or $h-\delta p+\beta p_{\mathrm{C}}<-\alpha \delta p_{\mathrm{C}}$ should be satisfied. The first-order derivative of $t_{2}$ on $p, \partial t_{2} / \partial p=$ $\alpha \delta p_{\mathrm{C}} /\left(h-\delta p+\beta p_{\mathrm{C}}\right)\left(h-\delta p+\beta p_{\mathrm{C}}+\alpha \delta p_{\mathrm{C}}\right)$ shows that when the signs of the two terms in the denominator are opposite, $t_{2}$ will increase with $p$, but when the signs are the same, it will decrease when $p$ increases. In the former case, a group of inequalities including $h-\delta p+\beta p_{\mathrm{C}}>0$ accompanied with $h-\delta p+\beta p_{\mathrm{C}}<-\alpha \delta p_{\mathrm{C}}$ or $0>h-\delta p+\beta p_{\mathrm{C}}>-\alpha \delta p_{\mathrm{C}}$ must be satisfied. However, all of the above has failed to hold according to the assumptions. In the latter case, either $h-\delta p+\beta p_{\mathrm{C}}>0$ or $h-\delta p+\beta p_{\mathrm{C}}<-\alpha \delta p_{\mathrm{C}}$ should be satisfied, and at this moment $t_{2}$ will be enlarged when $p$ increases. On the other side, solving the first derivative on $p_{\mathrm{C}}$, we have $\partial \underline{t}_{2} / \partial p=\alpha(h-p \delta) /\left(h-\delta p+\beta p_{\mathrm{C}}\right)\left(h-\delta p+\beta p_{\mathrm{C}}+\alpha \delta p_{\mathrm{C}}\right)$; thus, in the second case mentioned above, if $h-\delta p+\beta p_{\mathrm{C}}>0$ and $h-\delta p>0, \underline{t}_{2}$ will increase with either $p$ or $p_{\mathrm{C}}$. Similarly, if $h-\delta p<0, t_{2}$ will decline with an increasing $p$; when $h-\delta p+\beta p_{\mathrm{C}}<-\alpha \delta p_{\mathrm{C}}$ and $h-\delta p<0, \underline{t}_{2}$ will decrease when $p_{\mathrm{C}}$ increases. On the whole, Lemma 3 can be reached.

\section{Proof of Proposition 4}

The implementation of the maximum production strategy at the beginning of the cycle requires a satisfaction on the inequality $\delta p+\beta p_{\mathrm{C}}-h>\left(\delta e^{T \delta}\left(2 \theta r_{\max }+\alpha p_{\mathrm{C}}\right)\right) /\left(e^{T \delta}-e^{t \delta}\right)$. Evidently, as time passes, $\delta e^{T \delta}\left(2 \theta r_{\max }+\alpha p_{\mathrm{C}}\right) /\left(e^{T \delta}-e^{t \delta}\right)$ increases with $t$. Thus, when $t$ becomes larger, the above condition may not be fulfilled, and when the inequality sign reverses, the production rate will decline into the intermediate level. The switching (reversing) time can be easily derived as $\bar{t}_{3}=$ $\log \left[e^{T \delta}\left(1+\delta\left(\alpha p_{\mathrm{C}}+2 r_{\max } \theta\right) /\left(h-\delta p+\beta p_{\mathrm{C}}\right)\right)\right] / \delta$.

\section{Conflict of Interests}

The authors declare that they have no financial and personal relationships with other people or organizations that can inappropriately influence their work; there is no professional or other personal interests of any nature or kind in any product, service, and/or company that could be construed as influencing the position presented in this paper or its review.

\section{Acknowledgments}

This research is supported by the National Natural Science Foundation of China through Grant no. 71171205 and the Fundamental Research Funds for the Central Universities.

\section{References}

[1] B. C. Field, Environmental Economics: An Introduction, McGraw-Hill, New York, NY, USA, 2nd edition, 1997.

[2] S. S. Sana, "The stochastic EOQ model with random sales price," Applied Mathematics and Computation, vol. 218, no. 2, pp. 239248, 2011.

[3] S. S. Sana, "An EOQ model of homogeneous products while demand is salesmen's initiatives and stock sensitive," Computers \& Mathematics with Applications, vol. 62, no. 2, pp. 577-587, 2011.

[4] S. S. Sana, "An EOQ model for salesmen's initiatives stock and price sensitive demand of similar products-a dynamical system," Applied Mathematics and Computation, vol. 218, no. 7, pp. 3277-3288, 2011.

[5] S. S. Sana, "The EOQ model-a dynamical system," Applied Mathematics and Computation, vol. 218, no. 17, pp. 8736-8749, 2012.

[6] F. A. Bukhari and A. El-Gohary, "Optimal control of a production-maintenance system with deteriorating items," Journal of King Saud University-Science, vol. 24, pp. 351-357, 2012.

[7] L. Shoude, "Optimal control of production-maintenance system with deteriorating items, emission tax and pollution R\&D investment," International Journal of Production Research, vol. 52, no. 6, pp. 1787-1807, 2014.

[8] J.-J. Laffont and J. Tirole, "Pollution permits and compliance strategies," Journal of Public Economics, vol. 62, no. 1-2, pp. 85125, 1996.

[9] M. A. L. Caetano, D. F. M. Gherardi, and T. Yoneyama, "Optimal resource management control for $\mathrm{CO}_{2}$ emission and reduction of the greenhouse effect," Ecological Modelling, vol. 213, no. 1, pp. $119-126,2008$

[10] I. Dobos, "Production strategies under environmental constraints: continuous-time model with concave costs," International Journal of Production Economics, vol. 71, no. 1-3, pp. 323330, 2001.

[11] K. J. Arrow and S. Karlin, "Production over time with increasing marginal costs," in Studies in the Mathematical Theory of Inventory and Production, K. J. Arrow, S. Karlin, and H. Scarf, Eds., chapter 4, Stanford University Press, Stanford, Calif, USA, 1958.

[12] I. Dobos, "Production strategies under environmental constraints in an Arrow-Karlin model," International Journal of Production Economics, vol. 59, no. 1, pp. 337-340, 1999. 
[13] I. Dobos, "The effects of emission trading on production and inventories in the Arrow-Karlin model," International Journal of Production Economics, vol. 93-94, pp. 301-308, 2005.

[14] I. Dobos, "Tradable permits and production-inventory strategies of the firm," International Journal of Production Economics, vol. 108, no. 1-2, pp. 329-333, 2007.

[15] K.-H. Lee, "Integrating carbon footprint into supply chain management: The case of Hyundai Motor Company (HMC) in the automobile industry," Journal of Cleaner Production, vol. 19, no. 11, pp. 1216-1223, 2011.

[16] W. B. Gray and R. J. Shadbegian, "Environmental regulation, investment timing, and technology choice," Journal of Industrial Economics, vol. 46, no. 2, pp. 235-256, 1998.

[17] C. Chen and G. E. Monahan, "Environmental safety stock: the impacts of regulatory and voluntary control policies on production planning, inventory control, and environmental performance," European Journal of Operational Research, vol. 207, no. 3, pp. 1280-1292, 2010.

[18] R. Subramanian, S. Gupta, and B. Talbot, "Compliance strategies under permits for emissions," Production and Operations Management, vol. 16, no. 6, pp. 763-779, 2007.

[19] X. Gong and S. X. Zhou, "Optimal production planning with emissions trading," Operations Research, vol. 61, no. 4, pp. 908924, 2013.

[20] R. Carmona, M. Fehr, J. Hinz, and A. Porchet, "Market design for emission trading schemes," SIAM Review, vol. 52, no. 3, pp. 403-452, 2010.

[21] R. C. Baker and T. L. Urban, "A deterministic inventory system with an inventory-level-dependent demand Rate," The Journal of the Operational Research Society, vol. 39, no. 9, pp. 823-831, 1988.

[22] T. Urban, "Inventory model with an inventory-level-dependent demand rate and relaxed terminal conditions," Journal of the Operational Research Society, vol. 43, no. 7, pp. 721-724, 1992.

[23] T. L. Urban, "Inventory models with inventory-level-dependent demand: a comprehensive review and unifying theory," European Journal of Operational Research, vol. 162, no. 3, pp. 792804, 2005.

[24] A. Ramudhin, A. Chaabane, M. Kharoune, and M. Paquet, "Carbon market sensitive green supply Chain network design," in Proceedings of the IEEE International Conference on Industrial Engineering and Engineering Management (IEEM '08), pp.10931097, Singapore, 2008.

[25] A. Diabat and D. Simchi-Levi, "A carbon-capped supply chain network problem," in Proceedings of the IEEE International Conference on Industrial Engineering and Engineering Management, IEEM 2009, pp. 523-527, IEEE, Beijing, China, December 2009.

[26] M. I. Kamien and N. L. Schwartz, Dynamic Optimization, vol. 31 of Advanced Textbooks in Economics, North-Holland, Amsterdam, The Netherlands, 2nd edition, 1991. 


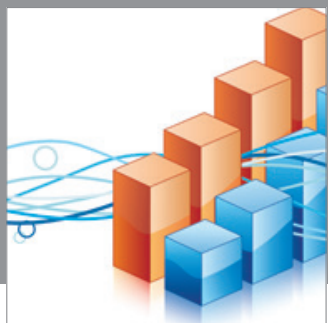

Advances in

Operations Research

mansans

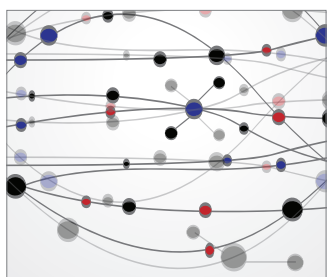

The Scientific World Journal
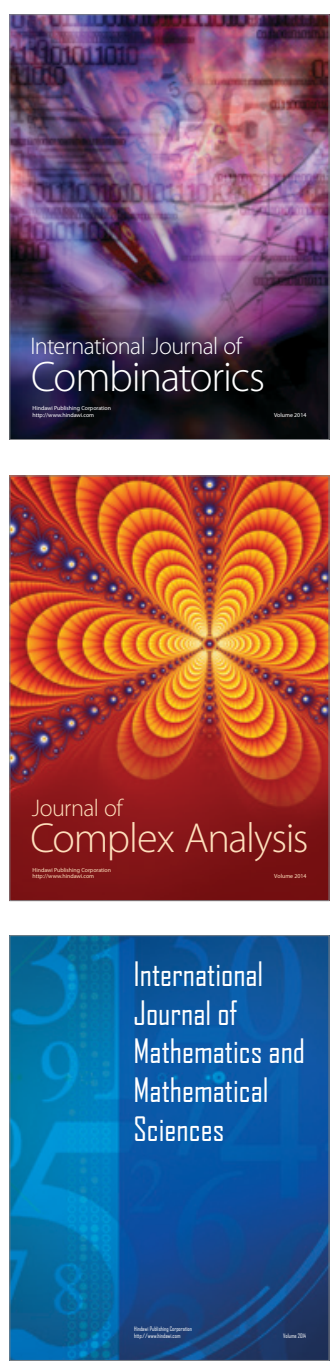
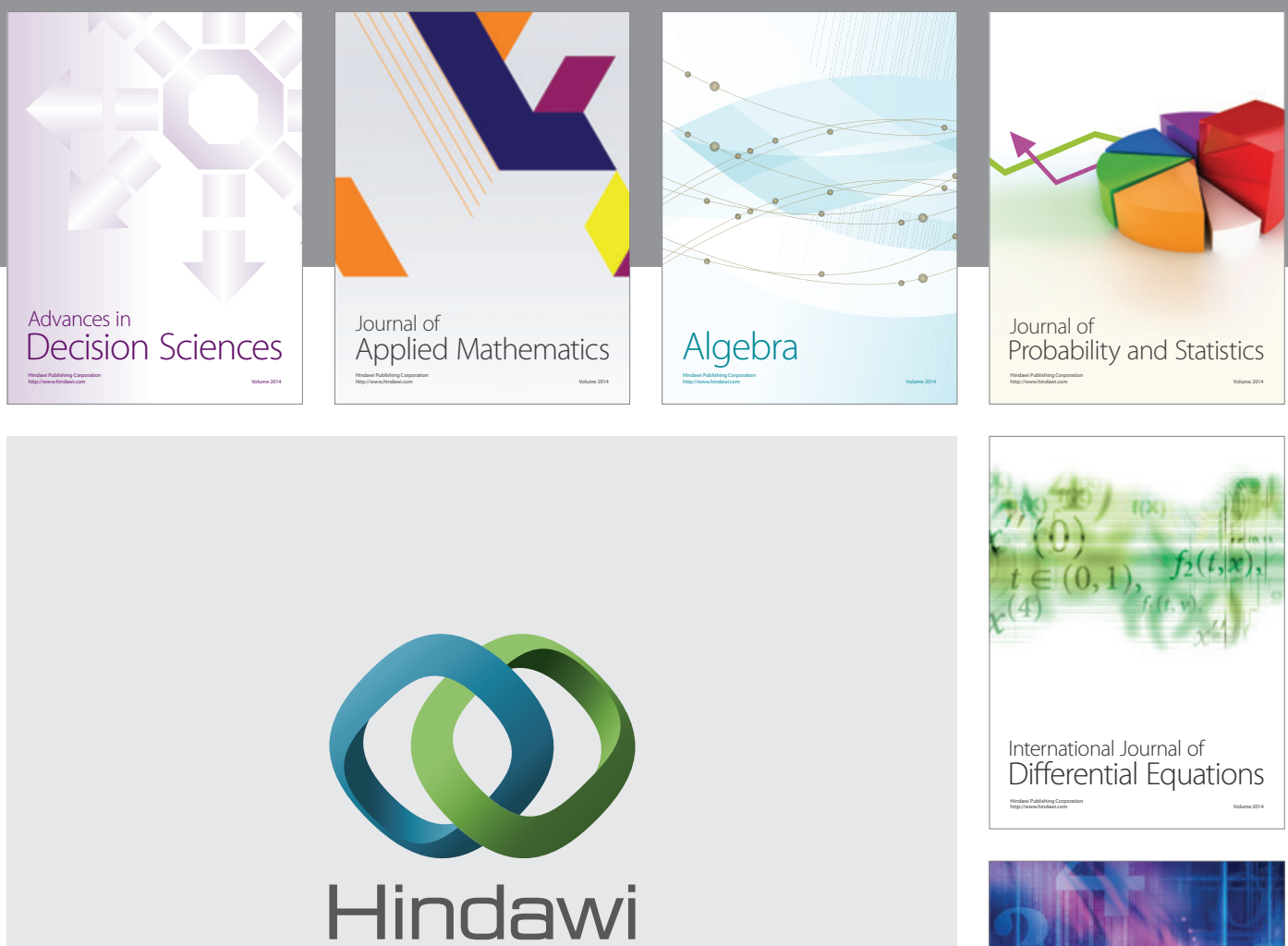

Submit your manuscripts at http://www.hindawi.com
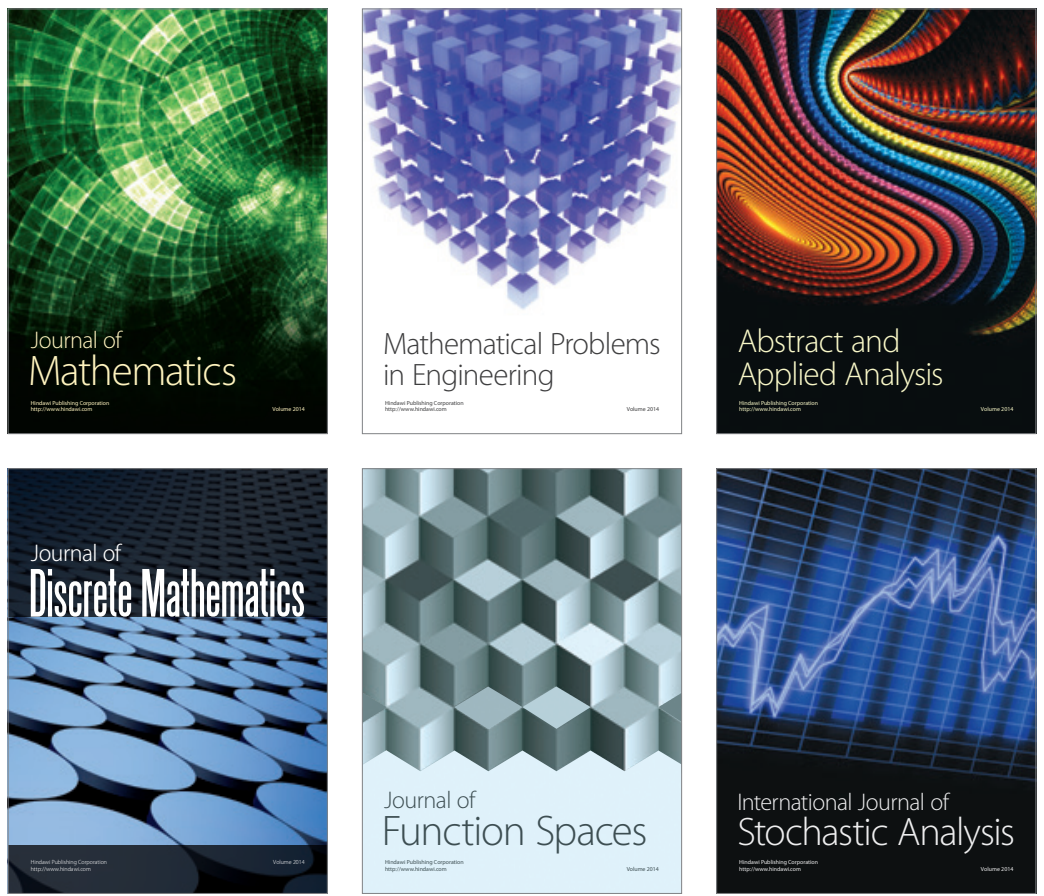

Journal of

Function Spaces

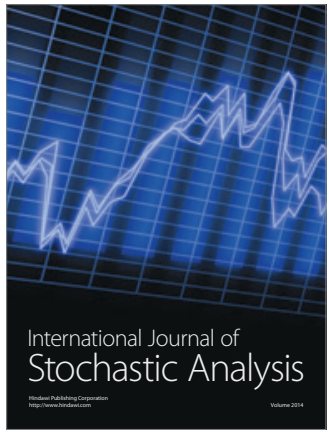

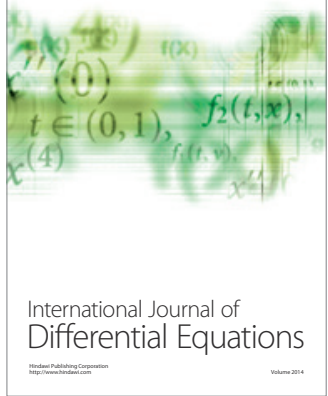
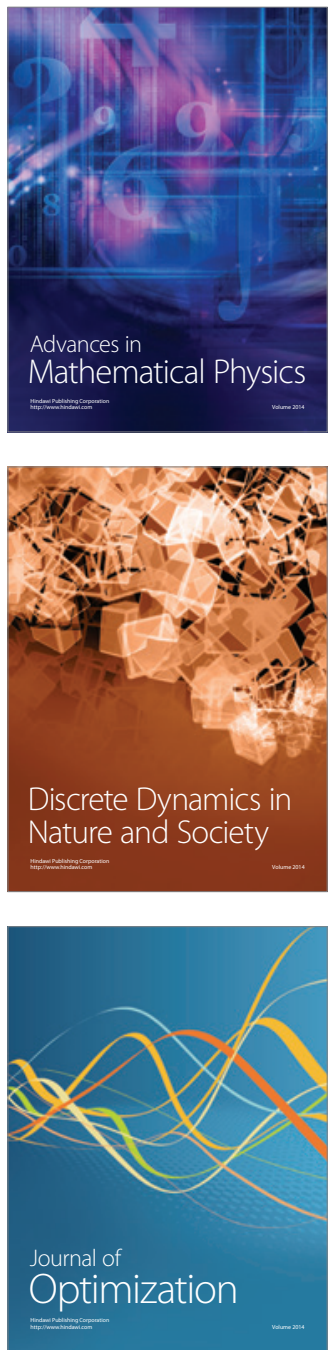